\title{
PERANCANGAN MESIN PENGADUK SAS ( BAHAN POKOK ) GAS AIR MATA
}

\author{
Agus Subagiyono \& Nurida Finahari \\ Jurusan Teknik Mesin Universitas Widyagama Malang \\ Email : nfinahari@widyagama.ac.id
}

\begin{abstract}
ABSTRAK
Perusahaan industri alat utama sistem pertahanan (alutsista) adalah perusahaan yang memproduksi produk militer dan produk komersial, Salah satu mesin yang ada di perusahaan industri alutsista adalah mesin pengaduk SAS (bahan pokok) gas air mata. Mesin ini berfungsi mencampurkan SAS gas air mata yang menghasilkan bahan pokok gas air mata yang homogen. Masalah yang timbul dalam pembuatan bahan pokok gas air mata ini untuk mencapai hasil yang homogen adalah masih manual, yaitu dengan pencampuran bahan pokok secara langsung oleh operator. Akibatnya sistem produksi tidak bisa bekerja secara optimal karena memerlukan waktu yang lama, kapasitas berkurang dan resiko bahaya lebih tinggi terhadap operatornya. Demi terwujudnya proses yang aman dan homogen maka diperlukan perancangan mesin pengaduk SAS gas air mata. Perancangan ini menggunakan metode Pahl and Beitz. Proses perancangan sistem yang digunakan secara garis besar terdiri dari tahap-tahap : Penjabaran Tugas, Perancangan dengan Konsep, Perancangan Wujud, dan Perancangan Secara Terperinci. Dengan mengikuti alur tahapan perancangan, didapatkan 5 varian desain yang dievaluasi mengikuti 9 kriteria. Hasil evaluasi menjadi dasar untuk memilih varian 2 sebagai desain terbaik untuk mesin pengaduk, yaitu menggunakan tangki horisontal, pengaduk screw, transmisi gear box dan penggerak motor listrik. Analisis teknis terhadap varian ini menghasilkan faktor keamanan 93,86 sehingga dapat dinyatakan layak dan aman untuk beroperasi pada kapasitas produksi 360 ton/shift.
\end{abstract}

Kata Kunci : Alutsista, SAS, Gas Air Mata, Metode Perancangan Pahl and Beitz, Homogen.

\section{PENDAHULUAN}

Perancangan adalah kegiatan awal dari suatu rangkaian kegiatan dalam proses pembuatan produk. Pada tahap perancangan tersebut dibuat keputusan-keputusan penting yang mempengaruhi kegiatan lain yang menyusulnya. Dalam melaksanakan tugas merancang, perancang memakai dan memanfaatkan ilmu dasar teknik, hasil- hasil penelitian, informasi dan teknologi, yang semuanya dalam versi pengembangan dan kemajuan yang mutakhir.

Perancangan dan pembuatan produk adalah dua kegiatan manunggal. Artinya rancangan hasil kerja tidak ada gunanya jika rancangan tersebut tidak dibuat, sebaliknya pembuat tidak dapat merealisasikan benda teknik tanpa terlebih dahulu dibuat gambar rancangannya. Diambil kesimpulan bahwa gambar rancangan produk adalah hasil akhir perancangan, dan merupakan dasar atau titik awal pembuatan produk oleh pembuat produk. Dapat dinyatakan disini bahwa pembuatan atau penyusunan gambar rancangan produk oleh perancang dicapai melalui fase-fase dalam proses perancangan yang panjang.

Proses perancangan memanfaatkan pengalaman dan pengetahuan tentang perancangan, serta semua pengetahuan yang terkait dengan produk dan pembuatan produk yang sedang dirancang. Dalam proses perancangan perlu adanya gambar teknik yang berfungsi sebagai media komunikasi efektif sehingga informasi lengkap tentang pembuatan peralatan dapat dipahami oleh pembuat. Disamping itu pada proses pembuatannya membutuhkan tahapan-tahapan pembuatan dari segi ide hingga menjadi sebuah mesin yang beroperasi.

Perusahaan industri alat utama sistem pertahanan (alutsista) adalah perusahaan yang memproduksi produk militer dan produk komersial, Salah satu mesin yang ada di perusahaan industri alutsista adalah mesin pengaduk SAS (bahan pokok) gas air mata. Mesin ini berfungsi mencampurkan SAS gas air mata yang menghasilkan bahan pokok gas air mata yang homogen. Masalah yang timbul dalam pembuatan bahan pokok gas air mata ini untuk mencapai hasil yang homogen adalah masih manual, yaitu dengan pencampuran bahan pokok secara langsung oleh operator. Akibatnya sistem produksi tidak bisa bekerja secara optimal karena memerlukan waktu yang lama, kapasitas berkurang dan resiko bahaya lebih tinggi terhadap operatornya. Demi terwujudnya proses yang aman dan homogen maka diperlukan perancangan mesin pengaduk SAS gas air mata. Perancangan ini menggunakan metode Pahl and Beitz (Pahl \& Beitz, 1995).

Dalam proses perancangan banyak sekali model perancangan yang diajukan oleh para perancang, tetapi kebanyakan model yang lebih rumit sering mengaburkan tujuan utama dari perancangan dengan mencampurkan antara detail 
dari berbagai masalah dan aktivitas dalam melakukan pekerjaan rancangan. Salah satu model yang telah disempurnakan dikemukakan oleh Pahl and Beitz. Model ini berdasarkan pada tahap-tahap perhitungan sebagai berikut :

1. Klarifikasi dari masalah, mengumpulkan informasi tentang kebutuhan untuk diwujudkan dalam produk akhir dan juga mengumpulkan informasi tentang batasan masalah.

2. Membuat konsep perancangan, menetapkan fungsi struktur, penelitian untuk pemecahan masalah yang sesuai, penggabungan kedalam beberapa konsep.

3. Perwujudtan rancangan, dimulai dari konsep, para perancang membuat bentuk serta membuat produk atau sistem dengan pertimbangan teknik dan ekonomi.

4. Rincian rancangan, penyususnan bentuk, dimensi dan sifat - sifat umum dari setiap komponen akhir yang berisi spesifikasi material, kelayakan teknik dan ekonomi. Pemeriksaan kembali semua gambar dan dokumen produksi yang telah dihasilkan.

Tujuan dari perancangan mesin pengaduk ini, berdasarkan permasalahan yang telah dijelaskan sebelumnya adalah untuk mempercepat proses produksi dan menghasilkan campuran bahan gas air mata yang merata dan homogen. Tahapan tujuan perancangan dari mesin pengaduk SAS (bahan pokok) gas air mata ini meliputi:

1. Mempelajari dan memahami metodologi perancangan berbasis fungsional.

2. Mengaplikasikan metode perancangan berbasis fungsional pada perancangan mesin pengaduk SAS gas air mata untuk menghasilkan campuran bahan pokok yang merata dan homogen. Metode yang digunakan adalah metode perancangan $G$. Pahl and W. Beitz.

3. Melakukan perancangan detil mesin pengaduk SAS gas air mata.

Manfaat dari penelitian ini adalah dapat mengetahui cara merancang pengaduk sas gas air mata yang menghasilkan campuran bahan pokok gas air mata yang homogen, sehingga dapat menghasilkan produk yang berkualitas.

\section{METODOLOGI}

Penelitian ini mengikuti tahapan-tahapan yang dijelaskan dalam sub-sub bahasan berikut.

\section{Perancangan Mesin Pengaduk SAS}

Perancangan mesin pengaduk SAS gas air mata ini menggunakan metode perancangan yang disusun oleh Gerhardt Pahl dan Wolfgang Beits. Proses perancangan yang digunakan ini secara garis besar terdiri dari tahap-tahap : a. Penjabaran Tugas (Clarification of Task)

b. Perancangan Dengan Konsep (Conceptual Design)

c. Perancangan Wujud (Embodiment Design)

d. Perancangan Secara Terperinci (Detail Design).

Tahapan proses perancangan ini dijelaskan pada diagram alir dalam Gambar 1.

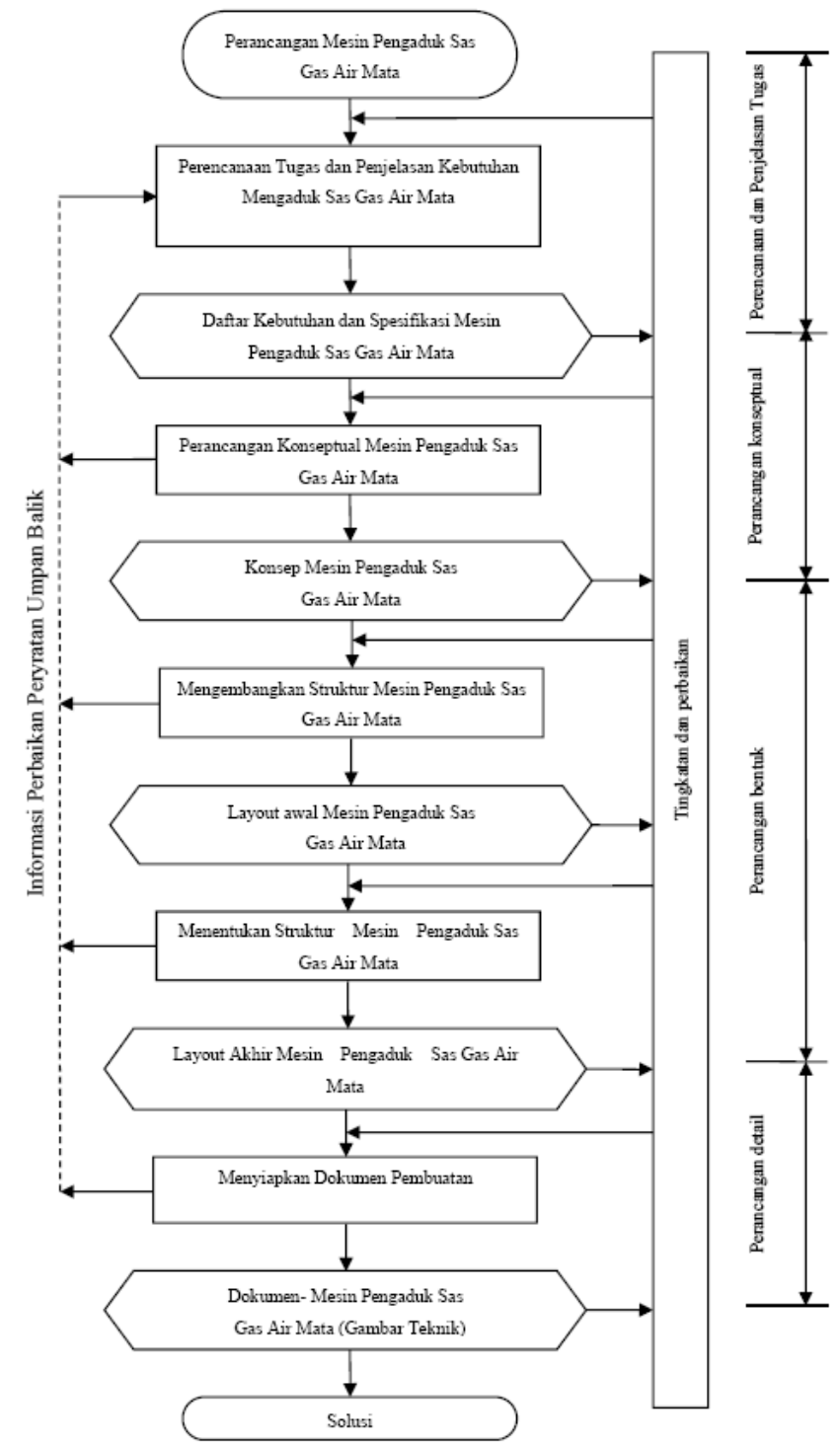

Gambar 1. Diagram Alir Perancangan (Pahl \& Beits, 1995)

\section{Fase Perencanaan dan Penjabaran}

Dalam fase ini diterangkan kebutuhan perencanaan dan penjabaran mesin pengaduk SAS gas air mata. Langkah-langkah yang terdapat pada fase pertama menurut prosesnya adalah:

\section{a. Analisis Keadaaan Mesin Pengaduk}

Ditinjau dari masukan dan keluarannya, mesin pengaduk akan mendapatkan masukan berupa bahan-bahan kimia yang halus, dengan keluaran merupakan campuran bahan baku yang siap dijadikan SAS untuk disusun menjadi gas air mata. Mesin pengaduk yang ada saat ini hasil dari pengadukannya kurang merata karena 
pengadukan dilakukan dalam jumlah banyak dan dengan menggunakan cara manual. Kondisi ini menimbulkan banyak kekurangan pada hasil produksi dan berbahaya bagi operator.

Dari kondisi mesin pengaduk saat ini dapat diidentifikasi kebutuhan tentang waktu pengadukan yang lebih cepat dengan hasil yang lebih maksimal. Berdasarkan pernyataan analisis keadaan diatas maka diperlukan beberapa langkah analisis kebutuhan untuk memperjelas tugas perancangan mesin. Langkah-langkah analisis kebutuhan itu terdiri dari :

- Spesifikasi tenaga penggerak, dipilih berbasis penggerak motor untuk mendapatkan kestabilan dan kontinyuitas yang lebih tinggi dari tenaga manusia

- Standar penampilan, diarahkan untuk mendapatkan konstruksi yang nyaman, aman dan mudah dioperasikan. Spesifikasi yang diinginkan Perusahaan Alutsista adalah untuk kapasitas $30 \mathrm{~kg} /$ proses untuk jangka waktu 30 menit atau sekitar $360 \mathrm{~kg} / \mathrm{shift}$ kerja

- Pertimbangan teknis perancangan mengacu pada kekuatan konstruksi mesin. Yang diinginkan adalah kuat dengan proses finishing baik sehingga meningkatkan masa pakai, proses perakitan mudah sehingga perawatannya nanti juga mudah dan murah

- Pertimbangan ergonomis, dimana mesin yang didesain tidak lagi menggunakan tenaga manusia, sederhana tetapi proporsional dengan fungsinya, khususnya terkait dengan proses pengadukan.

- Pertimbangan lingkungan mengarah pada kriteria bebas polusi dan tidak bising

- Pertimbangan keselamatan kerja harus bias memastikan bahwa setiap komponen mesin pengaduk memiliki fungsi pengaman terhadap potensi kecelakaan kerja

\section{b. Memformulasikan Desain Mesin Pengaduk}

Dari hasil analisis keadaan awal dan beberapa pertimbangan kebutuhan terhadap mesin pengaduk dapat dirumuskan capaian-capaian desain yang harus dipenuhi, yaitu :

- ada potensi untuk meningkatkan kualitas dan kuantitas hasil pengadukan

- proses pengadukan diharapkan lebih cepat

- meningkatkan efektifitas dan efisiensi proses

\section{c. Analisis Persyaratan Produk}

Beberapa prinsip solusi mesin pengaduk yang terbaik untuk pengolahan SAS gas air mata dibedakan menjadi 2 kelompok kriteria, yaitu :

- Kriteria kebutuhan wajib yang harus dipenuhi adalah mampu mengaduk SAS gas air mata dengan waktu yang relatif cepat dan hasil yang maksimal, harus mudah dan aman dalam pengoperasiannya, hasil produksi lebih berkualitas dan prosesnya lebih efisien.

- Kriteria harapan yang dinginkan terdapat pada hasil perancangan adalah perawatan dan perbaikannya mudah, harga pembuatan mesin lebih murah dibandingkan dengan harga pasaran, komponen-komponen yang dibutuhkan oleh mesin diharapkan dapat dengan mudah di dapat di pasaran atau dibuat dengan biaya yang terjangkau, dan penampilan (estetika) mesin menarik.

\section{Fase Perancangan Konseptual}

Fase ini merupakan bagian dari proses perancangan dimana dilakukan identifikasi masalah utama, melalui langkah-langkah berikut :

a. mengindentifikasi masalah-masalah penting

b. menentukan struktur fungsi produk

c. mencari prinsip-prinsip kerja produk

d. membentuk beberapa alternatif produk

e. evaluasi terhadap kriteria teknis dan ekonomis

\section{Fase Perancangan Bentuk Mesin}

Dari fase-fase sebelumnya dapat dikembangkan beberapa varian desain yang memenuhi persyaratan produk dan lulus kriteria konseptual. Varian-varian desain tersebut dapat diuji dan dieliminasi sehingga dapat diperoleh kombinasi terbaik yang bisa ditampilkan dalam bentuk layout terbaik. Layout desain terakhir yang didapatkan harus menyediakan sarana pemeriksaan fungsi, kekuatan dan kelayakan tempat.

\section{Fase Perancangan Detail}

Pada tahap ini bentuk mesin, dimensi, karakteristik komponen, spesifikasi material, pengecekan ulang berdasarkan kelayakan teknik dan ekonomi, seluruh gambar serta dokumendokumen produksi telah dihasilkan. Dalam hal ini diperhatikan juga adanya keterkaitan umum yang terdapat pada sistem benda teknik yaitu:

- Kaitan fungsi (Functional Interrelationship), yaitu keterkaitan antara masukan dan keluaran dari suatu sistem untuk melakukan kerja tertentu yang berhubungan dengan lingkungan sekitar.

- Kaitan kerja (Phisical Interrelationship), yaitu hubungan dimana kerja merupakan bagian dari proses fisika yang dipilih berdasarkan adanya efek fisika geometri seperti dimensi, struktur dan ciri-ciri material.

- Kaitan bentuk (Form Interrelationship), realisasi bentuk dari bahan menjadi struktur yang dilengkapi penataan lokasi dan pemilihan gerak.

- Kaitan sistem (System Interrelationship), dimana gambar teknik menampilkan bagian 
dari suatu sistem yang menyeluruh dari perancangan akhir.

\section{HASIL DAN PEMBAHASAN}

Dengan mengacu pada kriteria kebutuhan dan kriteria harapan, konsep produk dikembangkan menjadi perancangan produk dengan pendekatan black box. Konsep itu dikembangkan melalui transformasi energi untuk merealisasikan produk yang telah didefinisikan. Transformasi energi tersebut dapat dijelaskan melalui diagram blok fungsi yang selanjutnya dibuat menjadi matrik morfologi sebagai susunan alternatif fungsi yang merealisasikan transformasi tersebut. Gambar 2 menunjukkan struktur fungsi menurut black box, sementara gambaran kinerja tiap komponen ditunjukkan pada Gambar 3.

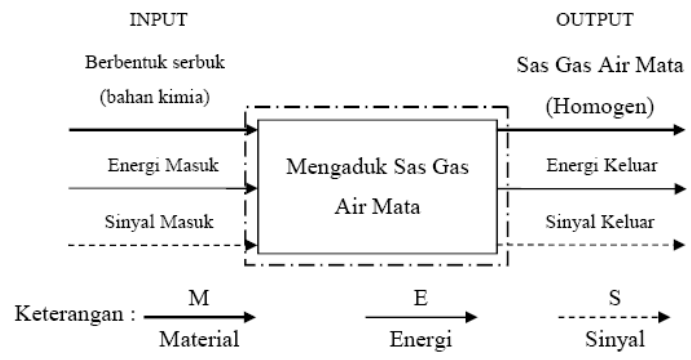

Gambar 2 : Struktur fungsi mesin pengaduk SAS gas air mata (Mc. Leod,1995)

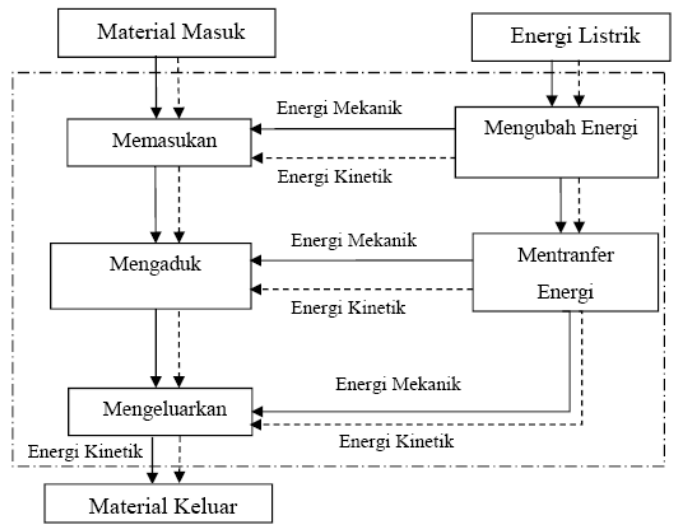

Gambar 3 : Struktur sub fungsi mesin pengaduk sas gas air mata. Material yang dimasukan adalah beberapa bahan kimia yang sudah diayak (Powder) dan Celluloid Glasso. Untuk material yang dikeluarkan berupa SAS gas air mata yang sudah homogen (Gilang, 2016)

Sub-sub fungsi diatas dijelaskan sebagai berikut:

1. Pemasukan : terdiri dari lubang masukan tanki yang bisa ditutup pada saat proses pengadukan dan dibuka pada saat memasukkan material.

2. Pengubah energi : pengubah energi ini adalah sumber energi putar untuk mesin pengaduk. Energi putar ini dapat diperoleh dari penggerak menggunakan motor listrik.

3. Pentransfer energi : bagian ini diantaranya menghubungkan pengubah energi dengan poros pengaduk dan mereduksi putaran yang diterima dari sumber energi putar.
4. Pengaduk : berguna mengaduk material yang masuk pada tangki, yang dapat menghasilkan campuran material yang homogen.

5. Pengeluaran : proses pengeluaran material yang sudah jadi dari tangki dilakukan dengan memberikan pintu di atas tangki.

Prinsip-prinsip kinerja fungsional tersebut kemudian diterapkan pada beberapa alternatif solusi yang mungkin. Proses ini ditunjukkan pada Tabel 1.

Tabel 1. Beberapa alternatif solusi

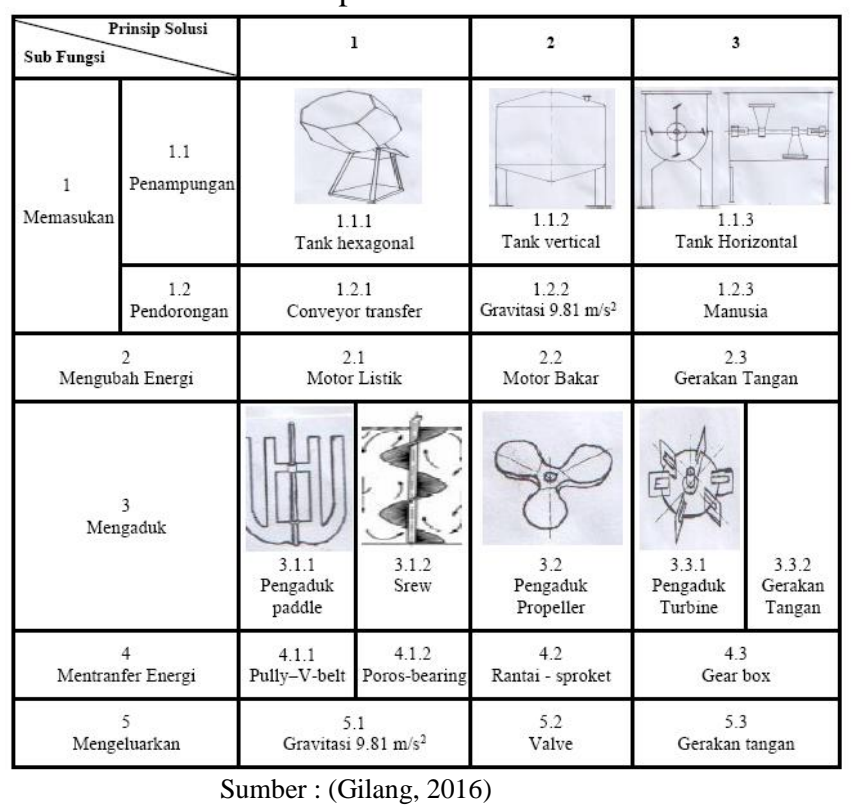

Alternatif-alternatif solusi tersebut selanjutnya diterjemahkan menjadi varian-varian produk yang digambarkan dalam bentuk skema desain menggunakan Program AutoCAD 2D sebagaimana tampak pada Gambar 4a-e.

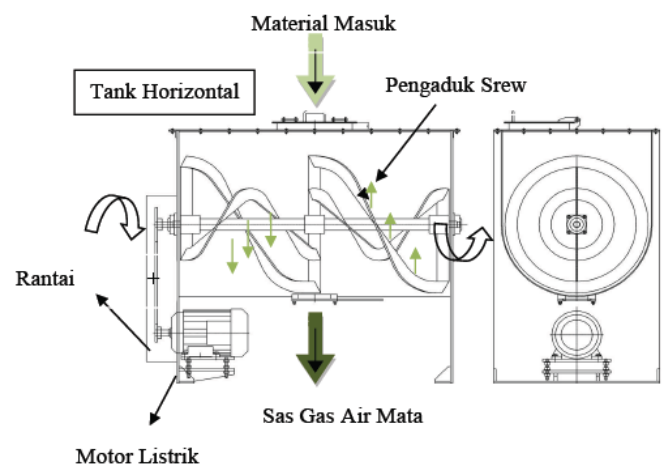

a. Varian 1 : Material masuk yang sudah dihaluskan dan diayak, dicampur celulloid glasso. Masuk ke dalam tangki horizontal secara manual dengan bantuan operator mesin. Untuk mengaduk SAS gas air mata ini digunakan pengaduk srew yang berlawanan arah pengaduk. Penggerak srew mesin ini menggunakan rantai + sprocket untuk mentransfer energi dari motor listrik yang berperan sebagai tenaga penggerak. Konsep varian 1 : (1.1.3-1.2.32.1-3.1.2-4.2-5.2) 


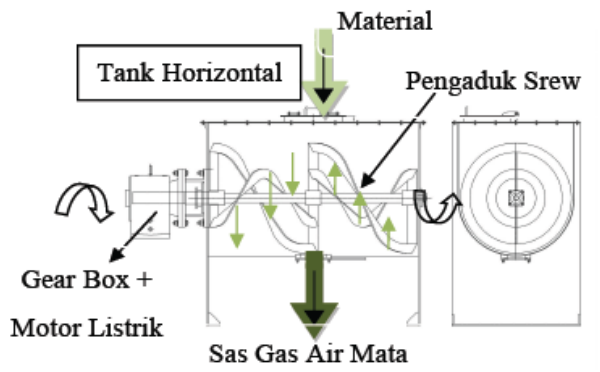

b. Varian 2 menggunakan prinsip kerja varian 1 hanya dengan pembeda pemanfaatan gear box sebagai pentransfer energi gerak dari motor listrik. Konsep varian 2 : (1.1.3-1.2.3-2.13.1.2-4.3-5.2)

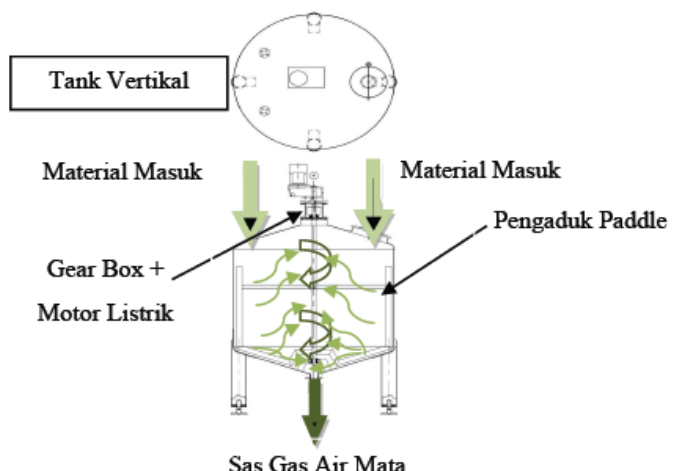

c. Varian 3 menggunakan prinsip kerja varian 2 hanya dengan pembeda penggunaan paddle sebagai pengaduk. Konsep varian $3:(1.1 .2-1.2 .3-2.1-3.1 .1-4.3-5.2)$.

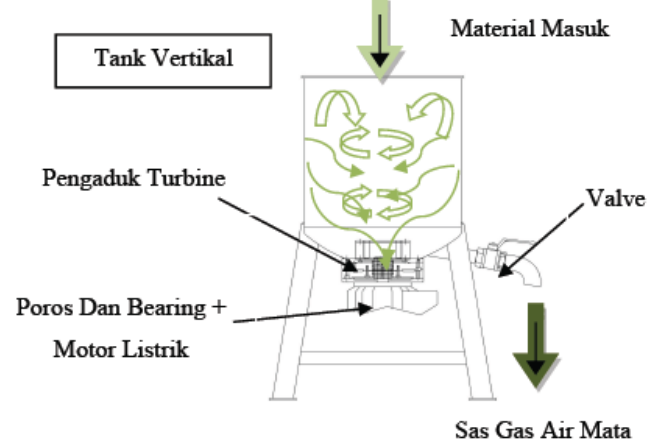

d. Varian 4 : Material masuk yang sudah dihaluskan dan diayak, dicampur celulloid glasso. Masuk ke dalam tank vertikal secara manual dengan bantuan operator mesin. Untuk mengaduk gas air mata ini digunakan pengaduk turbin. Penggerak turbin mesin ini menggunakan poros + bearing dengan motor listrik berperan sebagai sumber tenaga penggerak. Konsep varian 4 : (1.1.2-1.2.3-2.1-3.3.14.1.2-5.2). Varian ini didesain sebagai varian referensi.

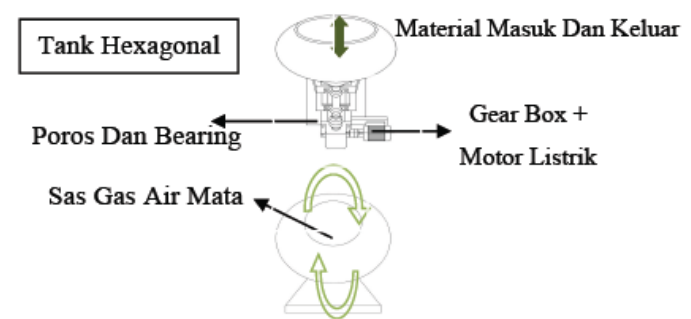

e. Varian 5 menggunakan tangki heksagonal dengan pengaduk model adukan tangan. Penggerak kombinasi poros + bearing dan gear box. Konsep varian 5 : (1.1.2-1.2.3-2.1-3.3.2-4.1.2$5.3)$.

Gambar 4 : Varian-varian produk yang didesain (Hasil Desain)
Proses pemilihan varian desain produk dilakukan melalui evaluasi konsep produk berdasarkan matrik keputusan. Kriteria perbandingan yang digunakan adalah:

1. Aman bagi operator

2. Aman lingkungan

3. Biaya produksi diharapkan seminimal mungkin.

4. Komponen strandar

5. Kekuatan material dikhususkan pada sifat tidak mudah aus dan dilakukan proses powder coating.

6. Kapasitas mesin dapat memenuhi kebutuhan

7. Mudah operasi

8. Feature menarik dan memiliki nilai jual lebih dari segi estetika bentuk.

9. Mudah dirakit

Kriteria tersebut diberi nilai variasi sesuai keinginan penggunaan dan perancang, berdasarkan tingkat kebutuhan. Rentangnya nilainya adalah 1-6. Nilai variasi ditampilkan pada Tabel 2 .

Tabel 2. Nilai variasi kriteria pemilihan desain

\begin{tabular}{|c|l|c|}
\hline No & \multicolumn{1}{|c|}{ Kriteria } & Nilai \\
\hline 1 & Aman bagi operator & 5 \\
\hline 2 & Aman bagi lingkungan & 3 \\
\hline 3 & Biaya produksi murah & 4 \\
\hline 4 & Komponen yang standar & 2 \\
\hline 5 & Material tahan lama & 1 \\
\hline 6 & Kapasitas mesin & 2 \\
\hline 7 & Mudah dioperasikan & 2 \\
\hline 8 & Feature yang menarik & 2 \\
\hline 9 & Mudah dirakit & Sumber : (Fishburn, 1967; McCrimmon, 1968)
\end{tabular}

Hasil penilaian terhadap 5 varian desain produk ditampilkan pada Tabel 3. Tabel evaluasi tersebut merupakan rekapitulasi penilaian operator dan perancang. Adapun contoh cara pembacaan tabel untuk evaluasi No. 1 adalah sebagai berikut : varian 1 mendapatkan nilai $S$ (nilai sama dengan referensi), varian 2 mendapat nilai $S$ (nilai sama dengan referensi), varian 3 mendapat nilai + (nilai lebih baik dari referensi, varian 4 merupakan referensi untuk penilaian dan varian 5 mendapat nilai - (nilai dibawah referensi). untuk pembacaan selanjutnya adalah sama dengan kriteria evaluasi nomor 1. Hasil penjumlahan kriteria evaluasi menunjukkan bahwa varian 2 mendapatkan nilai tertinggi sebesar 8. Maka varian desain inilah yang dipilih untuk diwujudkan menjadi produk jadi. 
Tabel 3. Hasil evaluasi varian desain

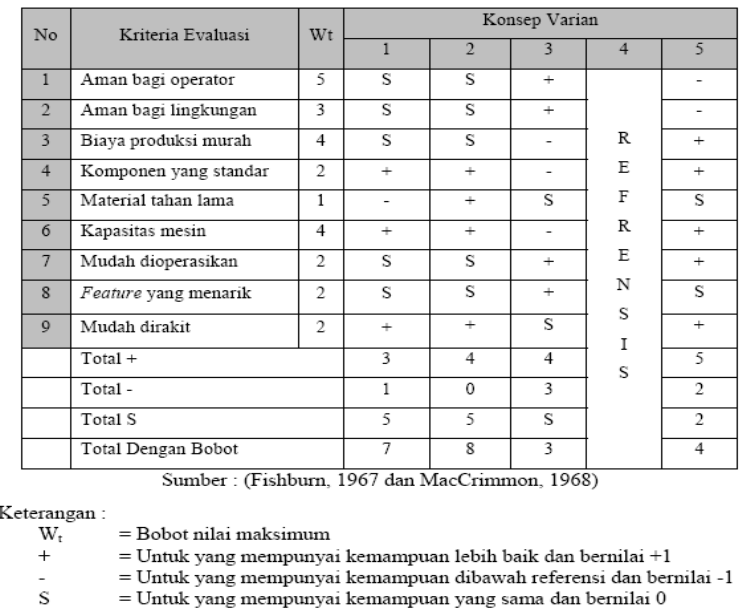

Konsep desain varian 2 yang terpilih selanjutnya dirancang detail menggunakan perhitungan teknis elemen mesin, termasuk perhitungan gaya dan analisis kegagalan material, hingga didapat desain akhir (Gambar 5-8) .

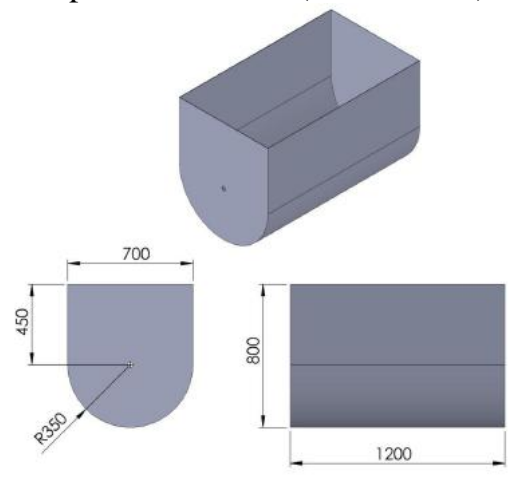

Gambar 5. Bentuk dan dimensi tangki
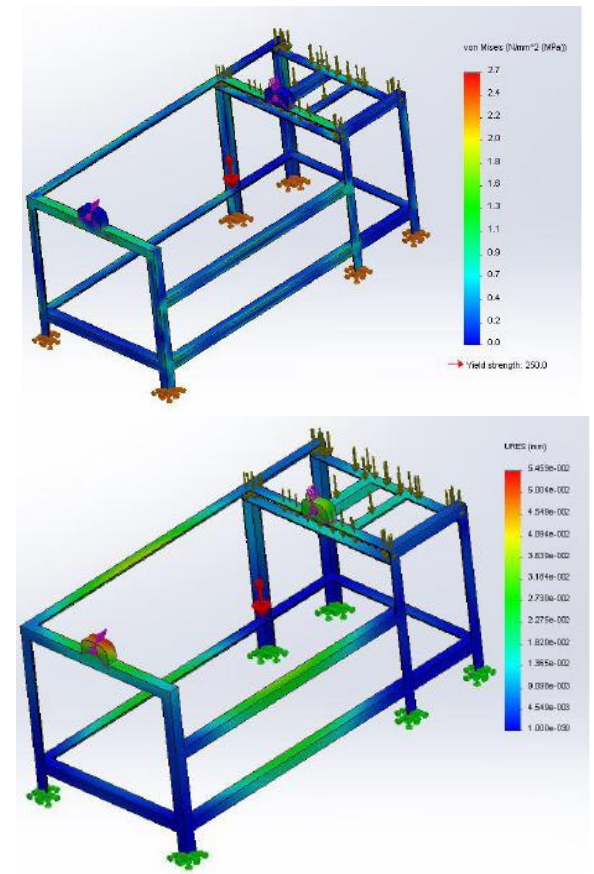

Gambar 6. Hasil analisis gaya dan deformasi rangka dengan menggunakan Program SolidWork

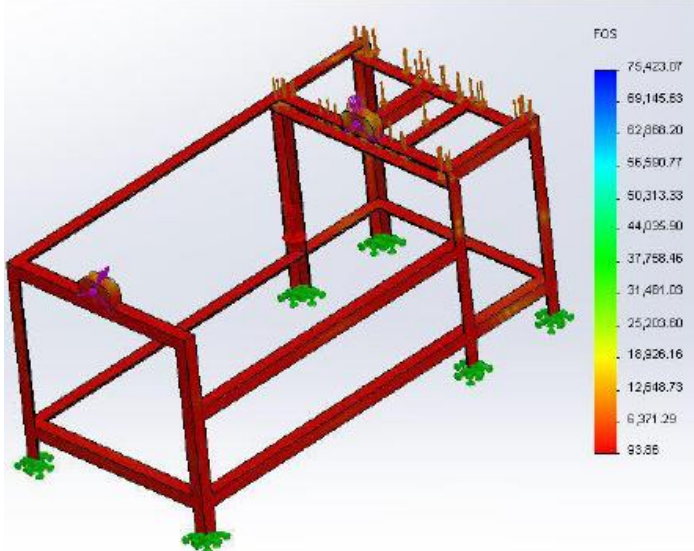

Gambar 7. Analisis faktor keamanan desain. Diperoleh faktor keamanan 93.8\%. Desain dinyatakan aman secara konstruksi.
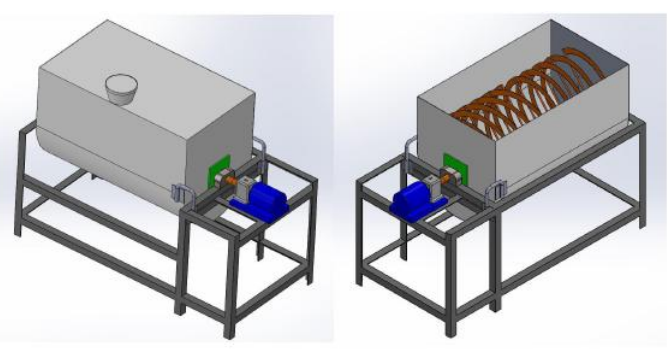

Gambar 8. Hasil akhir desain (Hasil Desain)

Hasil analisis teknis untuk tangki mesin pengaduk didasari fungsinya sebagai tempat penampung SAS yang akan diaduk, selain itu juga sebagai pengarah SAS agar tetap berada pada radius putaran poros pengaduk. Dimensi dari tangki ini adalah panjang $1200 \mathrm{~mm}$, lebar 350 $\mathrm{mm}$, dan tinggi $450 \mathrm{~mm}$. Bahan tangki digunakan dari plat stainless steel dengan tebal $2 \mathrm{~mm}$ agar dapat menahan berat SAS sebesar $30 \mathrm{~kg}$ dan menahan getaran yang terjadi yang ditimbulkan oleh pengaduk pada saat proses pengadukan SAS gas air mata.

Hasil dari perhitungan teknis menunjukkan gaya puntir total pada proses pengadukan sebesar $51.32 \mathrm{~kg}$, maka kebutuhan daya motor penggerak $N=0,6 \mathrm{HP}$. Dengan melihat analisis kebutuhan daya tersebut, maka dipilihlah tenaga penggerak berupa motor listrik yang mempunyai daya $0,75 \mathrm{HP}$. Hal tersebut didasarkan atas ketersediaan motor listrik di pasaran. Dengan pemakaian motor listrik yang mempunyai daya lebih dari kebutuhan, maka dapat diasumsikan mesin mampu untuk melakukan pengadukan SAS.

Mesin pengaduk SAS gas air mata ini menggunakan transmisi gear box, untuk rpm motor listrik 1400 dan putaran output 35, jadi digunakan ratio 40. Dengan daya yang akan ditransmisikan $(N)$ sebesar $0,75 \mathrm{HP}=0,5593 \mathrm{~kW}$, putaran poros pada pengaduk adalah $35 \mathrm{rpm}$, maka bahan poros yang digunakan pada mesin pengaduk ini dipilih jenis ST-60, dimana momen puntir yang terjadi sebesar $(T)=1211,5 \mathrm{~kg} . \mathrm{mm}$, 
kekuatan tarik bahan poros $(\sigma b)=60 \mathrm{~kg} / \mathrm{mm}^{2}$, tegangan geser yang dijinkan $\tau_{a}=5 \mathrm{~kg} / \mathrm{mm}^{2}=49$ $\mathrm{MPa}$, momen lentur $(\mathrm{M})=54000 \mathrm{~kg} . \mathrm{mm}$. Dengan melihat data hasil perhitungan ini, dapat diketahui bahwa diameter poros pengaduk yang dibutuhkan adalah sebesar 43,5 mm. Akan tetapi, dalam pembuatannya digunakan diameter sebesar 45 $\mathrm{mm}$. Hal tersebut dilakukan untuk menghemat waktu pembubutan bahan poros, agar konstruksi lebih stabil, poros lebih kuat, lebih mudah dalam pemilihan bearing karena mengacu ketersediaan di pasaran. Dari pertimbangan-pertimbangan tersebut dapat disimpulkan bahwa pemakaian diameter poros $45 \mathrm{~mm}$ akan memberikan lebih banyak keuntungan daripada kerugian akibat pemborosan bahan baku.

Rangka mesin pengaduk SAS gas air mata ini dipilih terdiri dari profil siku dengan ukuran $50 \mathrm{~mm}$ x $50 \mathrm{~mm}$ x $5 \mathrm{~mm}$. Dimensi rangka yaitu panjang $1800 \mathrm{~mm}$, lebar $850 \mathrm{~mm}$, tinggi 800 $\mathrm{mm}$. Rangka terbagi menjadi 3 bagian, yaitu bagian atas rangka yang merupakan dudukan poros pengaduk, bagian samping merupakan dudukan bagian motor listrik, dan bagian tengah merupakan dudukan tempat tangki. Bahan rangka yang digunakan adalah ST 37. Mengingat dimensi mesin pengaduk berskala sedang dengan beban yang kecil, maka bahan rangka ini cukup kuat untuk menahan beban dan getaran yang terjadi.

Beban pada dudukan motor sebesar $8 \mathrm{~kg}$, beban total pada dudukan poros sebesar $65 \mathrm{~kg}$. Tegangan geser yang terjadi pada rangka sebesar $2,7 \mathrm{MPa} \leq 250 \mathrm{MPa}$ tegangan geser ijin bahan, sehingga rangka dinyatakan aman/baik dan didapatkan faktor keamanan yang dimiliki oleh rangka mesin tersebut yaitu sebesar 93.86.

\section{KESIMPULAN}

Dengan menggunakan metode perancangan Pahl \& Beitz, dapat disusun beberapa kriteria desain yang menghasilkan 5 varian desain. Atas dasar kriteria evaluasi Fishburn \& McCrimmon ditetapkan desain terpilih adalah varian 2 untuk mesin pengaduk, menggunakan tangki horisontal, pengaduk screw, transmisi gear box dengan motor penggerak listrik. Analisis teknis atas varian tersebut menghasilkan faktor keamanan 93.86 sehingga dapat dinyatakan layak dan memenuhi standar keamanan, untuk kapasitas produksi 360 ton/shift.

\section{DAFTAR PUSTAKA}

Pahl, G. \& Beitz, W. 1988. Engineering Design: a systematic apporach. Verlag-London : Springer.

Mcleod. 1995. Sistem Informasi Manajemen. Jakarta: PT.Prenhalindo.

Sularso. 2013. Dasar Perencanaan dan Pemilihan Elemen mesin. Bandung: PT. AKA.

Fishburn, P.C. 1967. A Problem-based Selection of Multi-Attribute Decision Making Methods. Blackwell Publishing. New Jersey.

Maccrimmon, K.R. 1968. Decission making among multiple-attribute alternatives: a survey and consolidated approach. RAND memorandum, RM- 4823-ARPA.

Fitra. 2015. Merancang Screw Conveyor. http://fitra-berbagicerita.blogspot.co.id. diakses pada 21/11/2016

Fadhl. 2012. Yang Perlu Diketahui Tentang Gas Air. Mata. https://fadhlnews.wordpress.com. diakses pada 19/10/2016

Sudiyatno. 2006. Mesin Pencampur Bahan Pembuat Roti untuk Wirausaha Baru Produsen Roti Bakar Bandung. http://www.library.gunadarma.ac.id/. diakses pada $19 / 10 / 2016$

Voight, R. 1971. Buku Pelajaran Teknologi Farmasi. Yogyakarta: Gadjah Mada University Press.

Hardjomidjojo H. 2002. Metode Analisis Prospektif. Departemen Teknologi Industri Pertanian Fakultas Teknologi. Bogor. ITB.

Abadi. 2013 Mesin mixer agitator kapasitas 100 Baglog Mesin Press Baglog. http://www.mesinjamur.com. diakses pada $19 / 10 / 2016$

Harsokoesoemo, H.D. 2004. Pengantar Perancangan Teknik (Perancangan Produk). Edisi II. Bandung: ITB.

E.Shigley. Joseph. D.Mitchell dan Larry. 1995. Perencananaan Teknik Mesin jilid 2. Trans. Ir. Gandhi Harahap, M,Eng. Edisi keempat. Jakarta: PT. Erlangga.

Walas, S.M. 1988. Chemical Process Equipment Selection and Design. 3rd editions. Butterworth. United States of America.

Coulson and Richardson. 1955. Chemical Engineering. Vol. 2nd. Butterworth Heinemann : Boston.

Broadkey, R.S. and Herskey, H.C. 1988. TransPort Phenomena. A Unifiel Approach. International Edition. Mc Graw- Hill Book. Singapore.

Mahendratyo. 2016. Macam-Macam Sambungan (Las, Keling, Baut). https://madinglife.wordpress.com. diakses pada $25 / 10 / 2016$ 